\title{
Does re-amputation following lower extremity amputation in diabetic or dysvascular patients negatively affect survival?
}

\author{
Ozgur BAYSAL (D, Waziri Juma MSANGI ID, Berkin GUNAR (D), Bulent EROL (D) \\ ${ }^{1}$ Department of Orthopedics and Traumatology, Marmara University, Pendik Training and Research Hospital, Istanbul, Turkey.
}

Corresponding Author: Ozgur BAYSAL

E-mail: drozgurbaysal@gmail.com

Submitted: 28.06.2021 Accepted: 30.09.2021

\begin{abstract}
Objective: We aimed to investigate the characteristics of patients who underwent unilateral amputation due to diabetes and peripheral artery disease, as well as the risk factors that cause re-amputation, and to determine these patients' survival status and the risk factors for mortality.

Patients and Methods: This retrospective study included 133 patients who underwent amputation due to diabetes and peripheral arterial disease between 2012 and 2018. The etiology of amputation, the re-operation rate and time to re-operation following initial amputation, survival status and follow up results were accessed from hospital records.

Results: Twenty-eight patients underwent amputation due to peripheral arterial disease, whereas 105 patients had peripheral vasculopathy due to diabetes mellitus. The re-operation rate was $33.8 \%$, and the median period from initial surgery to the second surgery was six-weeks. Sixty-six deceased patients survived with a median of 6 months following initial operation.

Conclusion: The most crucial factor causing re-amputation was the non-healing wound problems. Patients with amputation should be followed up carefully for wound problems in the six weeks after surgery. Advanced age, American Society of Anesthesiologist grade 4 patients, associating neurological disease, low albumin level, low lymphocyte count and postoperative intensive care unit requirement were all poor prognostic factors for survival. Re-amputation had no negative effect on survival.

Keywords: Amputation, Diabetes mellitus, Lower extremity, Reoperation rate, Mortality, Peripheral arterial disease
\end{abstract}

\section{INTRODUCTION}

Wound problems on extremities may occur due to the complications of diabetes mellitus (DM) or peripheral artery disease (PAD). If wound problems are not treated appropriately in time, the infection can spread to deeper tissues of the entire lower extremity, and irreversible damage may develop in the extremity [1]. Conventional dressing, negative pressure wound therapy, debridement, and amputation can be applied for these wound problems depending on the wound's depth and the severity of the infection [2,3].

Patients diagnosed with DM or PAD should be informed about the prevention of foot wound problems. They should be followed up for foot examination at least once a year [4].Diabetic patients have a up to $25 \%$ risk of developing foot ulcers in whole life [5].Healing ulcers recur $40 \%$ within one year and $65 \%$ within five years [6]. PAD and DM are commonly associated with vasculopathy related amputations and are eight times more common than traumatic amputations [7].
We aimed to investigate the characteristics of patients who underwent unilateral amputation due to DM or PAD, as well as the risk factors that cause re-amputation in our institution and also to determine these patients' survival status and the risk factors that cause mortality.

\section{PATIENTS and METHODS}

This study was conducted upon the approval of Marmara University, School of Medicine Ethics Committee (09.2021.16). A retrospective review was done using the medical records of 262 patients who underwent amputation between 2012 and 2018. Patients with bilateral amputation $(n=27)$ and without regular follow-up $(n=13)$ were excluded from the study. The patients who underwent amputation due to malignant extremity tumors $(n=57)$ and trauma and trauma related complications $(n=32)$ were also excluded. The remaining 133 patients who

How to cite this article: Baysal O, Msangi WJ, Gunar B, Erol B. Does re-amputation following lower extremity amputation in diabetic or dysvascular patients negatively affect survival? Marmara Med J 2022: 35(1):73-78. doi: 10.5472/marumj.1059068 
underwent unilateral lower extremity amputation due to DM or PAD were included in this study.

Demographic characteristics of the patients (age, gender), comorbidities, nutritional status (albumin level), blood parameters [Complete blood count (CBC), hemoglobin (Hb) (g/ dl), glycated hemoglobin (HbA1c) (\%), C-reactive protein(CRP) $(\mathrm{mg} / \mathrm{dl})]$, the American Society of Anesthesiologists (ASA) grades, microbiological culture positivity, the etiology of amputation, need for reoperation, amputation level in the first operation, type of surgery (debridement, revision of the amputation to a higher level) performed for patients requiring a reoperation, postoperative intensive care unit (ICU) requirement after the first operation, the length of ICU stay, the length of hospital stay in the first operation, the time from the first operation to reoperation, the survival status of the patients, duration of follow-up were recorded from the patients' archive files.

The lower extremity amputation level of the patients was determined by preoperative Doppler ultrasonography or computed tomography angiography, and intraoperative observation of the tissue viability.

\section{Statistical Analysis}

Data analysis was carried out using SPSS, v. 22.0 software (SPSS Inc., Chicago, Illinois, USA). The study data were evaluated using descriptive statistical methods (mean, standard deviation, median, interquartile range, frequency, ratio, minimum, maximum). A Kolmogorov-Smirnov test, a Shapiro-Wilk test, and graphical assessments were used to test the normality of the quantitative data distribution. The Mann-Whitney $U$ test was used to compare continuous variables that were not distributed normally. Categorical variables were compared with Chisquared test, Fisher's Exact test, and Fisher-Freeman-Halton tests. A Kaplan Meier Survival analysis and Log-Rank test were used to evaluate the survival data. A p-value less than 0.05 was considered statistically significant.

\section{RESULTS}

The study included 133 patients who underwent amputation of the lower extremity at our clinic between 2012 and 2018 with a diagnosis of DM or PAD.

Characteristics of patients according to amputation etiology are shown in Table I.
Table I. Characteristics of the patients by amputation etiology

\begin{tabular}{|c|c|c|c|}
\hline Characteristics & Diabetes Mellitus & PAD & p \\
\hline Age (years) (Mean $\pm S d)$ & $63.67 \pm 9.97$ & $69.29 \pm 16.01$ & $0.019 \mathrm{a}$ \\
\hline Sex & & & \multirow{3}{*}{$0.136 b$} \\
\hline Men & $88(83.8 \%)$ & $20(71.4 \%)$ & \\
\hline Women & $17(16.2 \%)$ & $8(28.6 \%)$ & \\
\hline $\begin{array}{l}\text { The Need of Second } \\
\text { Operation }\end{array}$ & $37(35.2 \%)$ & $8(28.6 \%)$ & $0.508 \mathrm{~b}$ \\
\hline $\begin{array}{l}\text { Time from First } \\
\text { Operation to Second } \\
\text { Operation (month)* }\end{array}$ & $1.35(0.67-3.5)$ & $\begin{array}{l}1.75(0.78- \\
2.88)\end{array}$ & $0.823 \mathrm{a}$ \\
\hline Culture & & & \multirow{4}{*}{$0.526 c$} \\
\hline Positivity & $53(50.5 \%)$ & $11(39.3 \%)$ & \\
\hline Negative & $8(7.6 \%)$ & $3(10.7 \%)$ & \\
\hline NA & $44(41.9 \%)$ & $14(50 \%)$ & \\
\hline $\begin{array}{l}\text { Comorbidities } \\
(0 / 1 / 2 / 3 / 4)\end{array}$ & $0 / 28 / 36 / 28 / 13$ & $7 / 13 / 3 / 5 / 0$ & $<0.001 c$ \\
\hline CAD & $48(45.7 \%)$ & $8(28.6 \%)$ & $0.103 a$ \\
\hline CRD & $35(33.3 \%)$ & $2(7.1 \%)$ & $0.006 \mathrm{a}$ \\
\hline Neurologic & $13(12.4 \%)$ & $5(17.9 \%)$ & $0.534 \mathrm{~d}$ \\
\hline COPD & $8(7.6 \%)$ & $4(14.3 \%)$ & $0.277 \mathrm{~d}$ \\
\hline ASA grade & & & \multirow{4}{*}{$0.754 \mathrm{c}$} \\
\hline 2 & 18 & 5 & \\
\hline 3 & 67 & 16 & \\
\hline 4 & 20 & 7 & \\
\hline $\begin{array}{l}\text { Postoperative ICU } \\
\text { requirement }\end{array}$ & $40(38.1 \%)$ & $11(39.3 \%)$ & $0.908 \mathrm{~b}$ \\
\hline $\begin{array}{l}\text { Length of Stay in ICU } \\
(\text { day)* }\end{array}$ & $2(1-5)$ & $2(1-4)$ & $0.857 \mathrm{a}$ \\
\hline $\begin{array}{l}\text { Length of Stay in } \\
\text { hospital (day)* }\end{array}$ & $13(5-26.5)$ & $7.5(5-21.5)$ & $0.346 \mathrm{a}$ \\
\hline Survival Status & & & \multirow{3}{*}{$0.187 \mathrm{~b}$} \\
\hline Surviving & $56(53.3 \%)$ & $11(39.3 \%)$ & \\
\hline Deceased & $49(46.7 \%)$ & $17(60.7 \%)$ & \\
\hline Follow-up (month)* & $19(6.5-39.5)$ & $\begin{array}{c}17.35(4.15- \\
49.25)\end{array}$ & $0.842 \mathrm{a}$ \\
\hline
\end{tabular}

${ }^{a}$ Mann Whitney U Test, $b$ Pearson Chi-Square Test, c Fisher Freeman Halton Test, $d$ Fisher Exact Test

PAD: Peripheral Arterial Disease, CAD:Coronary Arterial Disease, CRD:Chronic Renal Disease, COPD; Chronic Obstructive Pulmonary Disease, ICU: Intensive Care Unit, ASA: American Society of Anesthesiologists

*: These data are presented as median IQR. Other data are number of patients. 
The distribution of amputation level in the first operation and type of surgery (debridement, revision of the amputation to a higher level) for re-operation of the patients are presented in Table II. The re-operation rates of patients who underwent above the knee amputations were significantly lower than those below the knee level amputations $(\mathrm{p}<0.001)$.

Table II. Characteristics of amputation level in the first operation, type of surgery (debridement, revision of the amputation, a higher level amputation). for.re-operation.

\begin{tabular}{|c|c|c|c|c|c|}
\hline First Operation & $\mathrm{n}(\%)$ & Re-operation & $\mathrm{n}(\%)$ & First Operation to Re-Operation & $\mathrm{n}(\%)$ \\
\hline $\begin{array}{c}\text { Finger amputation } \\
\text { TMA } \\
\text { BKA } \\
\text { AKA }\end{array}$ & $\begin{array}{l}15(11.2 \%) \\
28(21.1 \%) \\
58(43.6 \%) \\
32(24.1 \%)\end{array}$ & $\begin{array}{c}\text { Debridement } \\
\text { TMA } \\
\text { BKA } \\
\text { AKA } \\
\text { HLFA } \\
\text { Hip Disarticulation }\end{array}$ & $\begin{array}{c}15(11.3 \%) \\
1(0.8 \%) \\
11(8.3 \%) \\
16(12 \%) \\
1(0.8 \%) \\
1(0.8 \%)\end{array}$ & $\begin{array}{l}\text { Finger amputation to debridement } \\
\text { Finger amputation to TMA } \\
\text { Finger amputation to BKA } \\
\text { Finger amputation to AKA } \\
\text { TMA to debridement } \\
\text { TMA to BKA } \\
\text { TMA to AKA } \\
\text { BKA to debridement } \\
\text { BKA to AKA } \\
\text { AKA to debridement } \\
\text { AKA To HLFA } \\
\text { AKA to Hip disarticulation }\end{array}$ & $\begin{array}{l}1(2.2 \%) \\
1(2.2 \%) \\
4(8.9 \%) \\
1(2.2 \%) \\
3(6.7 \%) \\
7(15.6 \%) \\
2(4.4 \%) \\
8(17.8 \%) \\
13(28.9) \\
3(6.7 \%) \\
1(2.2 \%) \\
4(8.9 \%) \\
\end{array}$ \\
\hline
\end{tabular}

TMA: Trans-metatarsal amputation, BKA: Below the knee amputation, AKA:Above the knee amputation, HLFA: High Level Femoral Amputation

Table III. Assessments related to mortality in all cases

\begin{tabular}{|c|c|c|c|}
\hline Characteristics & Surviving & Deceased & $\mathrm{p}$ \\
\hline Age (years) $($ Mean \pm Sd) & $61.21 \pm 11.52$ & $68.55 \pm 10.69$ & $<0.001 \mathrm{a}$ \\
\hline Sex & & & $0.792 b$ \\
\hline Men & $55(82.1 \%)$ & $53(80.3 \%)$ & \\
\hline Women & $12(17.9 \%)$ & $13(19.7 \%)$ & \\
\hline The Need of Second Operation & $20(29.9 \%)$ & $25(37.9 \%)$ & $0.328 \mathrm{~b}$ \\
\hline Time from First Operation to Second Operation* & $1(0.67-3)$ & $1.5(0.85-3.5)$ & $0.475 \mathrm{a}$ \\
\hline Culture & & & $0.612 \mathrm{~b}$ \\
\hline Positivity & $34(50.7 \%)$ & $30(45.5 \%)$ & \\
\hline Negative & $4(6 \%)$ & $7(10.6 \%)$ & \\
\hline NA & $29(43.3 \%)$ & $29(43.9 \%)$ & \\
\hline Comorbidities $(0 / 1 / 2 / 3 / 4)$ & $2 / 22 / 24 / 14 / 5$ & $5 / 19 / 15 / 19 / 8$ & $0.296 \mathrm{c}$ \\
\hline CAD & $25(37.3 \%)$ & $31(47 \%)$ & $0.259 \mathrm{~b}$ \\
\hline CRD & $15(22.4 \%)$ & $22(33.3 \%)$ & $0.312 b$ \\
\hline Neurologic & $5(7.5 \%)$ & $13(19.7 \%)$ & $0.039 \mathrm{~b}$ \\
\hline COPD & $6(9 \%)$ & $6(9.1 \%)$ & $0.978 \mathrm{~b}$ \\
\hline Postoperative ICU requirement & $20(29.9 \%)$ & $31(47 \%)$ & $0.042 \mathrm{~b}$ \\
\hline Length of Stay in ICU (day) $)^{*}$ & $0(0-1)$ & $0(0-2)$ & $0.034 \mathrm{a}$ \\
\hline Length of Stay in hospital (day) ${ }^{*}$ & $10(5-21)$ & $13(5-27)$ & $0.139 \mathrm{a}$ \\
\hline ASA grade & & & $0.038 \mathrm{~b}$ \\
\hline 2 & $16(23.9 \%)$ & $7(10.6 \%)$ & \\
\hline 3 & $42(62.7 \%)$ & $41(62.1 \%)$ & \\
\hline 4 & $9(13.4 \%)$ & $18(27.3 \%)$ & \\
\hline Follow-up (month) & $32(16-60)$ & $6.5(1-29)$ & $<0.001 \mathrm{a}$ \\
\hline
\end{tabular}

a Mann Whitney U Test, $b$ Pearson Chi-Square Test, $c$ Fisher Freeman Halton Test

CAD: Coronary Arterial Disease, CRD:Chronic Renal Disease, COPD: Chronic Obstructive Pulmonary Disease, ICU: Intensive Care Unit, ASA: American Society of Anesthesiologists. *: These data are presented as median IQR. Other data are number of patients. 
Regarding the analyses of the blood parameters of the patients in the preoperative period, the median interquertile range (IQR) values of hemoglobin (g/dl), hematocrit (\%), white blood cell $\left(\mathrm{x}^{3} 0^{3} /\right.$ $\mu \mathrm{l})$, neutrophil $\left(\mathrm{x} 10^{3} / \mu \mathrm{l}\right)$, lymphocyte $\left(\mathrm{x} 10^{3} / \mu \mathrm{l}\right)$, platelet $\left(\mathrm{x} 10^{3} / \mu \mathrm{l}\right)$, albumin, and CRP (mg/L) were 10 (9-11), 30 (27.5-34), 10 (8-14), 8 (6-12), 1 (1-2), 314 (241-402), 3 (2-3), and 92.5 (38.75-149.5), respectively. Blood parameters were similar between patients with amputation due to $\mathrm{DM}$ and PAD. The median (IQR) value of HbAlc (\%) in diabetic patients was 7.65 (6.73-9.28). Thirty (22.6\%) patients with albumin values above $3.5 \mathrm{~g} / \mathrm{dL}, 14(10.5 \%)$ patients with $\mathrm{Hb}$ values above $12 \mathrm{~g} / \mathrm{dL}$ and 49 (36.8\%) patients with lymphocyte count above $1.5 \times 10^{3} / \mu \mathrm{l}$ were detected.

Among the 75 (56.4\%) patients who had wound culture test, culture positivity was detected in $64(85 \%)$. The single microorganism [S. Aureus $(\mathrm{n}=11)$, P. Aeruginosa $(\mathrm{n}=8)$, E. Coli $(n=5)$, E. faecium $(n=3)$, others $(n=7)]$, was detected in 34 patients $(53.1 \%)$ and polymicrobial microorganism (mostly gram-negative and anaerobic microorganisms) in 30 patients (46.9\%). It was determined that more wound culture tests were examined in the patients who needed a re-operation than those with a single surgery $(\mathrm{p}<0.001)$.

No statistically significant risk factors were found regarding the characteristics of recovery between patients who underwent a single surgery and those requiring re-operation $(\mathrm{p}>0.05)$. When these two groups were compared in terms of survival, there was no statistically significant difference $(\mathrm{p}=0.439)$.

Table III presents the assessments related to mortality in all cases. There were statistically significant differences between the blood parameters of the surviving and deceased patients, with lymphocyte count $(\mathrm{p}=0.044)$ and albumin level $(\mathrm{p}=0.018)$ being significantly lower in the deceased patients. Although, it was remarkable that a high CRP level had a higher mortality rate, this relationship was not statistically significant $(\mathrm{p}=0.056)$.

Among the 105 patients who underwent amputation due to DM, $56(53.3 \%)$ patients survived with a median survival time of $60 \pm 13.55$ months. 11 (39.3\%) of the 28 cases had an amputation due to PAD survived with a median survival time of $29 \pm 11.98$ months. When assessing survival status between the groups using a Log-Rank test, no statistically significant difference was noted between the two groups' survival curves $(p=0.298)$ (Figure 1). Sixty-six deceased patients survived with a median (IQR) value of 6 (1-29) months following the initial operation.

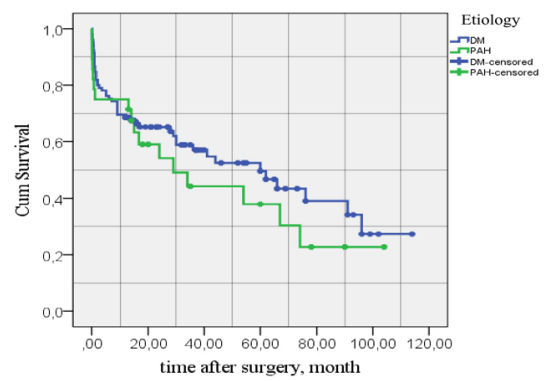

Figure 1. Kaplan Meier Analysis of patients undergoing amputation due to diabetes mellitus and peripheral arterial disease

\section{DISCUSSION}

We evaluated 262 patients who underwent extremity amputation in our clinic between 2012 and 2018 with various indications; $50.7 \%$ were due to $\mathrm{DM}$ or PAD. $80 \%$ of these patients were male, and the median age was 65 years. This rate was similar to reported amputation rates due to $\mathrm{DM}$ or PAD in the literature $[8,9]$.

There are no clearly defined criteria for determining the amputation level of a patient for whom an amputation decision is made due to $\mathrm{DM}$ or PAD [10]. Although, various invasive and non-invasive vascular methods have been reported in the literature for selecting the appropriate level of amputation [11], we think that the most crucial criterion for selecting amputation level is to evaluate both preoperative vascular imagines and observe the bleeding of tissues intraoperatively. Performing amputation at the distal level as much as possible aims to reduce the patient's energy during walking and improves the quality of life $[12,13]$. However, distal level amputation may cause wound problems and risk of re-operation [13]. The re-operation risk ratio was reported as $13.4-56 \%$ (average 16.3\%) in the literature [14]. In our study, the re-operation rate was $33.8 \%$, which was above the average re-operation rate reported in the literature. This high rate may have been due to our goal to preserve the most distal level as possible and to improve the patient's quality of life and facilitate mobilization. Also, amputation surgery is a form of treatment that is accepted very difficult in certain societies. It is reported that the psychosocial structure of patients is impaired after amputation surgery [15]. In our clinical practice, we also observed that patients' self-care after surgery had decreased significantly which might cause the need for a secondary surgery. On the other hand, as we found that reoperation did not affect the mortality rate, we considered this re-operation rates as reasonable. Patients who should undergo amputation at the possible distal level to avoid the impairment of their quality of life and functionality.

Many factors affect wound healing in patients after amputation surgery $[14,16-19]$. The median period from the initial surgery to the second surgery was six weeks in our study. 2-2590 days were reported in the literature from the first operation to reoperation [17]. The general opinion is that these patients should be closely followed-up within the first six months [20].Although, various risk factors for reoperation (coronary artery disease, chronic kidney failure, low albumin levels, low lymphocyte count, anemia) were reported $[13,16,17,21,22]$, we did not find a statistically significant relationship between the risk factors and re-operation in this study. This may be explained by the fact that the majority of our patients have already these risk factors. Also, it reveals the importance of performing the amputation operation at the appropriate level.

Mostly, gram-negative and anaerobic bacteria are responsible for serious deep wound infections and life-threatening conditions [23]. The microorganisms isolated from wound cultures of patients were primarily gram-negative bacteria in the current study. This situation may be explained by the chronicity of the diabetic wounds and previous antibiotic treatments. We 
did not perform any wound culture in patients who received preoperative antibiotic treatment. Culture positivity was detected in $64(85.3 \%)$ out of 75 patients.

When we examined the survival status of patients who underwent amputation due to $\mathrm{DM}$ or PAD, we found that $66(49.6 \%)$ of the patients died within a median of 6 months after the inital surgery. Comorbidity, older age and gramnegative microorganisms have been reported to be the factors that negatively affect the patients' survival $[23,24]$. The rate of comorbid disease was significantly higher in diabetic patients. The mean age of patients with PAD was statistically significantly higher than diabetic patients. The high mortality rate in patients amputated due to DM or PAD may be attributed to comorbid status of these patients and their advanced age.

The limitations of the present study include its single-center and retrospective study design, the lack of a control group, the small number of patients, the lack of cost analysis, and the operations were performed by different surgeons at our department.

In conclusion, the most critical factor for wound healing after amputation surgery, regardless of the risk factors reported in the literature, was amputation level. Patients with amputation should be followed up carefully for wound problems in the first six weeks after surgery. Older age, ASA-4 patients, with neurological disease, low albumin level, low lymphocyte count and postoperative ICU requirement were all poor prognosis criteria in terms of survival. Re-amputation surgery had no negative effect on survival.

\section{Compliance with the Ethical Standards}

Ethical Approval: Marmara University, School of Medicine Ethics Committee approved the study (protocol no: 09.2021.16).

Financial Support: The authors have no relevant financial information to close.

Conflict of Interest: The authors have no potential conflicts of interest to disclose.

Author Contributions: OB: Study design, data analysis, writing the article, WJM and BG: Data collection, data analysis, BE: Study design, writing the article, supervision. All authors read the article and approved the final version of the article.

\section{REFERENCES}

[1] Giurato L, Meloni M, Izzo V, Uccioli L. Osteomyelitis in diabetic foot: A comprehensive overview. World J Diabetes 2017;8:135-42. doi. 10.4239/wjd.v8.i4.135.

[2] Frykberg RG, Banks J. Challenges in the treatment of chronic wounds. Adv Wound Care (New Rochelle) 2015;4:560-82. doi: 10.1089/wound.2015.0635.

[3] Ceyhan Ö, Akutay S. Diyabetik hastalarda amputasyon sonrası yara iyileşmesi ve bakım. Sakarya Tıp Dergisi 2019;9:11-5. doi:10.31832/smj.496098

[4] Boulton AJ, Armstrong DG, Albert SF, et al. Comprehensive foot examination and risk assessment: a report of the task force of the foot care interest group of the American Diabetes
Association, with endorsement by the American Association of Clinical Endocrinologists. Diabetes Care 2008;31:1679-85. doi: $10.2337 / \mathrm{dc} 08-9021$

[5] Alavi A, Sibbald RG, Mayer D, et al. Diabetic foot ulcers: Part I. Pathophysiology and prevention. J Am Acad Dermatol 2014;70:1.e-18; quiz 9-20. doi: 10.1016/j.jaad.2013.06.055

[6] Armstrong DG, Boulton AJM, Bus SA. Diabetic foot ulcers and their recurrence. N Engl J Med 2017;376:2367-75. doi:10.1056/nejmra1615439.

[7] Varma P, Stineman MG, Dillingham TR. Epidemiology of limb loss. Phys Med Rehabil Clin N Am 2014;25:1-8. doi:10.1016/j. pmr.2013.09.001.

[8] Olgun N EAF, Çoşansu G, Çelik S. Diabetes mellitus. İçinde: Dahili ve Cerrahi Hastalıklarda Bakım. 4th ed. Ankara: Akademisyen Kitabevi, 2017:787-824.

[9] Konya P, Demirtürk N. Son üç yılda kliniğimizde izlenen diyabetik Ayak infeksiyonlarının değerlendirilmesi. Acta Medica Alanya 2017;1:11-4. doi:10.30565/medalanya.261700

[10] O'Brien PJ, Cox MW, Shortell CK, Scarborough JE. Risk factors for early failure of surgical amputations: an analysis of 8,878 isolated lower extremity amputation procedures. J Am Coll Surg 2013;216:836-42. doi: 10.1016/j.jamcollsurg.2012.12.041

[11] Kılıç B, Yücel AS, Yaman Ç, Hergüner G, Korkmaz M. Methods of determining the amputation level of lower extremity.EuroJ ExpBio 2014;4:55-60.

[12] van Schaik L, Geertzen JHB, Dijkstra PU, Dekker R. Metabolic costs of activities of daily living in persons with a lower limb amputation: A systematic review and meta-analysis. PLoS One 2019;14:e0213256. doi: 10.1371/journal.pone.0213256.

[13] Baumfeld D, Baumfeld T, Macedo B, Zambelli R, Lopes F, Nery C. Factors related to amputation level and wound healing in diabetic patients. Acta Ortop Bras 2018;26:342-5. doi:10.1590 /1413.785.2201826.051.73445

[14] Berlin MC, Wanivenhaus F, Kabelitz M, et al. Predictors for reoperation after lower limb amputation in patients with peripheral arterial disease. Vasa 2019;48:419-24. doi: 10.1024/0301-1526/a000796.

[15] Horgan O, MacLachlan M. Psychosocial adjustment to lowerlimb amputation: a review. Disabil Rehabil 2004;26:837-50. doi: 10.1080/096.382.8041000.170.8869.

[16] Gülcü A, Eli M, Karahan O, Aslan A. Analysis of routine blood markers for predicting amputation/reamputation risk in diabetic foot. Int Wound J 2020;17:1996-2004. doi:10.1111/ iwj.13491

[17] Wanivenhaus F, Mauler F, Stelzer T, Tschopp A, Böni T, Berli MC. Revision rate and risk factors after lower extremity amputation in diabetic or dysvascular patients. Orthopedics 2016;39:e149-54. doi:10.3928/01477.447.20151222-14

[18] Namgoong S, Jung S, Han SK, Jeong SH, Dhong ES, Kim WK. Risk factors for major amputation in hospitalised diabetic foot patients. Int Wound J 2016;13 Suppl 1:13-9.doi: 10.1111/ iwj.12526.

[19] Akan KH. Diyabetik ayakta ampütasyon.TOTBİD Dergisi2105; 14 , 421-32. doi:10.14292/totbid.dergisi.2015.62 
[20] Akçay S, Harman E, Satoğlu İS, Kurtulmuş A. Diyabetik ayak amputasyonlarında reamputasyon oranları [Rates and risk factors of diabetic foot reamputations]. Flora 2018; 23 , 202-7. doi: 10.5578/flora.67491

[21] Czerniecki JM, Thompson ML, Littman AJ, et al. Predicting reamputation risk in patients undergoing lower extremity amputation due to the complications of peripheral artery disease and/or diabetes. Br J Surg 2019;106:1026-34. doi: 10.1002/bjs.11160.

[22] Monge L, Gnavi R, Carnà P, Broglio F, Boffano GM, Giorda $\mathrm{CB}$. Incidence of hospitalization and mortality in patients with diabetic foot regardless of amputation: a population study. Acta Diabetologia 2020;57:221-8. doi: 10.1007/s00592.019.014128.

[23] Hartemann-Heurtier A, Robert J, Jacqueminet S, et al. Diabetic foot ulcer and multidrug-resistant organisms: risk factors and impact. Diabet Med 2004;21:710-5. doi: 10.1111/j.14645491.2004.01237.x.

[24] Stern JR, Wong CK, Yerovinkina M, et al. A meta-analysis of long-term mortality and associated risk factors following lower extremity amputation. Ann Vasc Surg. 2017;42:322-7. doi:10.1016/j.avsg.2016.12.015. 